\title{
Faktor yang Mempengaruhi Sertifikasi Halal Produk bagi Mahasiswa UIN Sunan Gunung Djati Bandung
}

\section{Factors affecting product halal certification for students of UIN Sunan Gunung Djati Bandung}

\section{Hestiani Fauziyyah}

Fakultas Ekonomi dan Bisnis Islam, UIN Sunan Gunung Djati Bandung

E-mail: hestianifauziyyah45@gmail.com

\section{Widiawati}

Fakultas Ekonomi dan Bisnis Islam, UIN Sunan Gunung Djati Bandung

E-mail: widiawati@uinsgd.ac.id

\section{Vemy Suci Asih}

Fakultas Ekonomi dan Bisnis Islam, UIN Sunan Gunung Djati Bandung E-mail: just.vemy@gmail.com

\begin{abstract}
This study discusses the relationship between the level of understanding of students as (X1) and awareness as (X2) of halal product certification as (Y) with UIN Bandung students as research targets. The method used in this study is a survey method with questionnaires distributed by getting 100 respondents with a quantitative approach. The purpose of this study is to find out how much influence it has on each variable with the results showing that student understanding (X1) bas a positive and significant effect on the Halal Certified Product variable (Y), and the influence of student awareness (X2) has a positive and significant impact on the Halal Certified Product variable. (Y). So the awareness and knowledge of students has a relationship with halal-certified products of 0.589. Calculated by correlation test and determination test. The level of understanding and awareness of students at this time is a consideration for halal product certification.
\end{abstract}

Keywords: understanding, awareness, balal certification, students

\section{Pendahuluan}

Islam telah mengatur segala aspek dalam kehidupan kita termasuk hukum dalam mengatur konsumsi umat muslim dengan menerapkan hukum dan kejelasan atas halal atau haramnya suatu barang. Sebagai mana yang telah tercantum dalam al-qur'an Surat Al-Baqarah ayat 173 yang berbunyi:

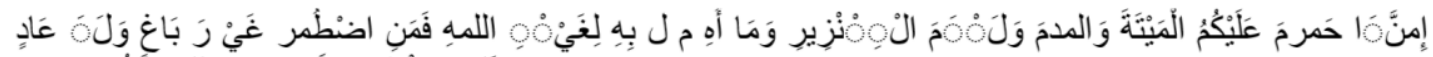

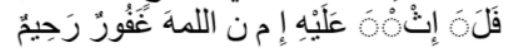

"Sesungguhnya Allah hanya mengharamkan bagimu bangkai, darah, daging babi, dan binatang yang (ketika disembelih) disebut (nama) selain Allah, Tetapi barangsiapa dalam keadaan terpaksa (memakannya) sedang dia tidak menginginkannya dan tidak (pula) melampaui batas, maka tidak ada dosa baginya, sesungguhnya Allah Maha Pengampun lagi Maha Penyayang".

Indonesia sebagai mayoritas muslim terbanyak di indonesia merupakan negara dengan populasi masyarakat muslim terbesar dunia. Menurut sensus penduduk Indonesia tahun 2010, penduduk Indonesia sebanyak 237641326 jiwa, 87,18\% memeluk agama Islam. Hal ini 
menyebabkan kebutuhan pangan halal menjadi mutlak sesuai dengan tuntunan ajaran Islam. Sementara itu baru sekitar 20\% dari total keseluruhan pangan telah disertifikasi halal oleh Majelis Ulama Indonesia (MUI) (Sutrisno, 2013). Dengan alasan ini kebutuhan muslim Indonesia dalam produk halal meningkat pada setiap tahunnya Indonesia harus memenuhi kebutuhan produk yang telah bersetifikasi halal. sudah menjadi tugas Lembaga MUI untuk memberikan kenyamanan, keamanan, keselamatan, dan kepastian ketersediaan produk halal bagi masyarakat dalam mengonsumsi dan menggunakan produk sehingga masyarakatkan mendapatkan ketenangan batin dalam mengkonsumsi dan menggunakan barang. Sertifkasi dan label pada produk pangan menjadi alat ukur dan kontrol agar tidak merugikan dan membahayakan konsumen (Hidayat dan Siradj, 2015).

Pemahaman tentang Agama ini makin membuat konsumen Muslim menjadi semakin selektif dalam pemilihan produk yang dikonsumsi. Khusus di Indonesia, terdapat Lembaga yang secara khusus bertugas melakukan audit terhadap produkproduk yang dikonsumsi oleh konsumen Muslim di Indonesia. Lembaga ini adalah Lembaga Pengkajian Pangan, Obat-Obatan dan Kosmetika Majelis Ulama Indonesia (LPPOMMUI).

Fakta dilapangan saat ini ketidak pahaman dalam mengkonsumsi suatu produk yang bersertifikasi halal justru terjadi pada kalangan para mahasiswa yang memiliki Pendidikan agama islam terkhusus pada mahasiswa Universitas Islam Negri Bandung yang memiliki tingkat konsumtif yang tinggi dalam suatu produk makanan, minuman, kosmetik dan lainnya. Dari berbagai uraian diatas, penulis tertarik dalam mengadakan penelitian dengan judul Tingkat Pemahaman Mahasiswa Universitas Islam Negri Bandung Terhadap Sertifikasi Produk Halal.

\section{Metode Penelitian}

Artikel ini menggunakan jenis penelitian kuantitatif, dan bersifat explanatory survey. Jenis penelitian ini digunakan untuk menjelaskan hasil survei terkait variabel independen dan dependen dengan menampilkan data dalam bentuk numerik dan menganalisisnya. Data yang digunakan pada penelitian ini adalah data primer, dimana data diperoleh langsung dari hasil kuesioner yang diisi oleh responden.

Pengukuran variabel menggunakan skala likert dengan ketentuan Sangat Setuju, Setuju, Netral, Tidak Setuju, dan Sangat Tidak Setuju. Adapun pengukuran variabel dapat diuraikan pada tabel berikut:

Tabel 1. Operasionalisasi Variabel Penelitian

\begin{tabular}{llll}
\hline \multicolumn{1}{c}{ Variabel } & \multicolumn{2}{c}{ Definisi Operasional } & \multicolumn{2}{c}{ Indikator } \\
\hline Pengetahuan Produk & Pengetahuan berarti keahlian & 1) & Mengerti hukum halal. \\
Halal & dan kemampuan yang & 2) & Merasa sudah bisa membedakan \\
& diperoleh seseorang atau & mana makanan dan minuman yang \\
kelompok melalui suatu & dihalalkan atau diharamkan oleh \\
pemahaman teori maupun & islam. \\
praktek suatu subjek (Hashim & 3) $\begin{array}{l}\text { Mengkonsumsi makanan halal adalah } \\
\text { dkk, 2014). }\end{array}$ \\
& 4al penting bagi. \\
& 4) $\begin{array}{l}\text { Bahan-bahan yang terdapat pada } \\
\text { produk halal merupakan bahan- }\end{array}$ \\
& bahan yang teruji kehalalannya \\
& ditandakan dengan adanya logo halal. \\
& 5) Logo halal menjadi pertimbangan \\
& saya dalam membeli produk \\
& makanan.
\end{tabular}




\begin{tabular}{|c|c|c|}
\hline Variabel & Definisi Operasional & Indikator \\
\hline Kesadaran Halal & $\begin{array}{l}\text { Tingkat pemahaman umat } \\
\text { islam dalam mengetahui isu- } \\
\text { isu yang berkaitan dengan } \\
\text { konsep halal. }\end{array}$ & $\begin{array}{l}\text { 1) Membeli produk berlabel halal } \\
\text { karena sadar adalah seorang muslim. } \\
\text { 2) Membeli produk berlabel halal } \\
\text { karena mengetahui tentang hukum } \\
\text { halal dan haram. } \\
\text { 3) Membeli produk berlabel halal } \\
\text { karena aman digunakan. } \\
\text { 4) Kebersihan produk bagian dari } \\
\text { penilaian kehalalan } \\
\text { 5engetahui proses pembuatan } \\
\text { makanan halal merupakan hal yang } \\
\text { sangat penting }\end{array}$ \\
\hline Sertifikasi hahal & $\begin{array}{l}\text { Sertifikasi halal merupakan } \\
\text { sebuah jaminan keamanan } \\
\text { bagi umat muslim untuk } \\
\text { dapat mengkonsumsi suatu } \\
\text { produk, memiliki peran yang } \\
\text { semakin penting dalam } \\
\text { permintaan global yang terus } \\
\text { meningkat untuk produk } \\
\text { halal }\end{array}$ & $\begin{array}{l}\text { 1) Mencari informasi tentang halal } \\
\text { produk dari teman, keluarga, iklan, } \\
\text { dan media massa. } \\
\text { 2) Pengetahuan mengenai logo halal. } \\
\text { 3) Pemilihan produk halal berdasarkan } \\
\text { logo halal. } \\
\text { 4) Pemilihan produk halal yang } \\
\text { didasarkan lembaga yang legal. } \\
\text { 5) Pengetahuan produk yang } \\
\text { menggunakan sertifikasi halal dari } \\
\text { negara lain. }\end{array}$ \\
\hline
\end{tabular}

\section{Hasil dan Pembahasan}

\subsection{Uji Validitas}

Pengujian validitas merupakan analisis terhadap suatu ukuran yang menunjukkan tingkat kevalidan dan kesahilan suatu kuesioner. Uji validitas mengunakan rumus teknik Kolerasi Product Moment. Dasar pengambilan keputusan adalah dinyatakan valid apalabila $r$-hitung $>r$-tabel. Dalam pengukuran penelitian ini dinyatakan valid dengan $r$ - tabel 0,1654 ( $d f=100-2)$, dimana ketentuannya r-hitung $>$ r-tabel dengan sig $<0,05$.

Tabel 2 : Uji Validitas Tingkat Pengetahuan Correlations Sumber: hasil output SPSS for windows versi 20

\begin{tabular}{llrrrrrr}
\hline & & X1_1 & X1_2 & X1_3 & X1_4 & X1_5 & Skor_Total \\
\hline \multirow{2}{*}{ X1_1 } & Pearson Correlation & 1 & $.544^{* *}$ & $.619^{* *}$ & .119 & .093 & $.745^{* *}$ \\
& Sig. (2-tailed) & & .000 & .000 & .240 & .358 & .000 \\
& $\mathrm{~N}$ & 100 & 100 & 100 & 100 & 100 & 100 \\
\hline \multirow{2}{*}{ X1_2 } & Pearson Correlation & $.544^{* *}$ & 1 & $.780^{* *}$ & .075 & $.229^{*}$ & $.837^{* *}$ \\
& Sig. (2-tailed) & .000 & & .000 & .456 & .022 & .000 \\
& $\mathrm{~N}$ & 100 & 100 & 100 & 100 & 100 & 100 \\
\hline \multirow{2}{*}{ X1_3 } & Pearson Correlation & $.619^{* *}$ & $.780^{* *}$ & 1 & $.248^{*}$ & $.278^{* *}$ & $.885^{* *}$ \\
& Sig. (2-tailed) & .000 & .000 & & .013 & .005 & .000 \\
& N & 100 & 100 & 100 & 100 & 100 & 100 \\
\hline X1_4 & Pearson Correlation & .119 & .075 & $.248^{*}$ & 1 & $.662^{* *}$ & $.462^{* *}$
\end{tabular}




\begin{tabular}{llrrrrrr}
\hline & & X1_1 & X1_2 & X1_3 & X1_4 & X1_5 & Skor_Total \\
\hline & Sig. (2-tailed) & .240 & .456 & .013 & & .000 & .000 \\
& $\mathrm{~N}$ & 100 & 100 & 100 & 100 & 100 & 100 \\
\hline \multirow{2}{*}{ X1_5 } & Pearson Correlation & .093 & $.229^{*}$ & $.278^{* *}$ & $.662^{* *}$ & 1 & $.514^{* *}$ \\
& Sig. (2-tailed) & .358 & .022 & .005 & .000 & & .000 \\
& $\mathrm{~N}$ & 100 & 100 & 100 & 100 & 100 & 100 \\
\hline \multirow{4}{*}{ Skor } & Pearson Correlation & $.745^{* *}$ & $.837^{* *}$ & $.885^{* *}$ & $.462^{* *}$ & $.514^{* *}$ & 1 \\
& Sig. (2-tailed) & .000 & .000 & .000 & .000 & .000 & \\
& $\mathrm{~N}$ & 100 & 100 & 100 & 100 & 100 & 100 \\
\hline
\end{tabular}

**. Correlation is significant at the 0.01 level (2-tailed).

*. Correlation is significant at the 0.05 level (2-tailed).

Pada pengujian validitas pertama adalah variabel tingkat pengetahuan. Pada variabel ini terdapat lima pernyataan yang digunakan dalam kuesioner. Berdasarkan hasil uji statistika, seluruh pernyataan dari variabel tingkat pengetahuan diketahui semuanya valid dimana pada pernyataan satu diperoleh $r$ - hitung sebesar 0,745 , pernyataan kedua sebesar 0.837 , pernyataan ketiga 0.885 , pernyataan keempat sebesar 0,462 , dan pernyataan kelima sebesar 0,514 . Keseluruhan hasil r-hitung $>$ r-tabel, sehingga dinyatakan valid.

Tabel 3: Uji Validitas Kesadaran Halal Correlations

\begin{tabular}{|c|c|c|c|c|c|c|c|}
\hline & & $\mathrm{X} 2 \_1$ & $\mathrm{X} 2 \_2$ & $\mathrm{X} 2 \_3$ & $\mathrm{X} 2 \_4$ & $\mathrm{X} 2 \_5$ & Skor \\
\hline \multirow{3}{*}{ X2_1 } & $\begin{array}{l}\text { Pearson } \\
\text { Correlation }\end{array}$ & 1 & $.466^{* *}$ & $.361^{* *}$ & $.361^{* *}$ & -.094 & $.629^{* *}$ \\
\hline & Sig. (2-tailed) & & .000 & .000 & .000 & .354 & .000 \\
\hline & $\mathrm{N}$ & 100 & 100 & 100 & 100 & 100 & 100 \\
\hline \multirow{3}{*}{ X2_2 } & $\begin{array}{l}\text { Pearson } \\
\text { Correlation }\end{array}$ & $.466^{* *}$ & 1 & $.457^{* *}$ & $.348^{* *}$ & -.038 & $.707^{* *}$ \\
\hline & Sig. (2-tailed) & .000 & & .000 & .000 & .706 & .000 \\
\hline & $\mathrm{N}$ & 100 & 100 & 100 & 100 & 100 & 100 \\
\hline \multirow{3}{*}{ X2_3 } & $\begin{array}{l}\text { Pearson } \\
\text { Correlation }\end{array}$ & $.361^{* *}$ & $.457^{* *}$ & 1 & $.755^{* *}$ & -.104 & $.799^{* *}$ \\
\hline & Sig. (2-tailed) & .000 & .000 & & .000 & .301 & .000 \\
\hline & $\mathrm{N}$ & 100 & 100 & 100 & 100 & 100 & 100 \\
\hline \multirow{3}{*}{ X2_4 } & $\begin{array}{l}\text { Pearson } \\
\text { Correlation }\end{array}$ & $.361^{* *}$ & $.348^{* *}$ & $.755^{* *}$ & 1 & -.138 & $.752^{* *}$ \\
\hline & Sig. (2-tailed) & .000 & .000 & .000 & & .170 & .000 \\
\hline & $\mathrm{N}$ & 100 & 100 & 100 & 100 & 100 & 100 \\
\hline \multirow{3}{*}{ X2_5 } & $\begin{array}{l}\text { Pearson } \\
\text { Correlation }\end{array}$ & -.094 & -.038 & -.104 & -.138 & 1 & $.229^{*}$ \\
\hline & Sig. (2-tailed) & .354 & .706 & .301 & .170 & & .022 \\
\hline & $\mathrm{N}$ & 100 & 100 & 100 & 100 & 100 & 100 \\
\hline \multirow{3}{*}{ Skor } & $\begin{array}{l}\text { Pearson } \\
\text { Correlation }\end{array}$ & $.629^{* *}$ & $.707^{* *}$ & $.799^{* *}$ & $.752^{* *}$ & $.229^{*}$ & 1 \\
\hline & Sig. (2-tailed) & .000 & .000 & .000 & .000 & .022 & \\
\hline & $\mathrm{N}$ & 100 & 100 & 100 & 100 & 100 & 100 \\
\hline
\end{tabular}

**. Correlation is significant at the 0.01 level (2-tailed).

*. Correlation is significant at the 0.05 level (2-tailed). 
Tabel 4: Uji Validitas Sertifikasi Halal Correlations

Sumber: hasil output SPSS for windows versi 20

\begin{tabular}{|c|c|c|c|c|c|c|c|}
\hline & & $Y_{-1}$ & Y_2 & Y_3 & $Y \_4$ & Y_5 & Skor_Y \\
\hline & Pearson Correlation & 1 & $.665^{* *}$ & $.902^{* *}$ & $.343^{* *}$ & $.392^{* *}$ & $.851^{* *}$ \\
\hline \multirow[t]{3}{*}{ Y_1 } & Sig. (2-tailed) & & .000 & .000 & .000 & .000 & .000 \\
\hline & $\mathrm{N}$ & 100 & 100 & 100 & 100 & 100 & 100 \\
\hline & Pearson Correlation & $.665^{* *}$ & 1 & $.779^{* *}$ & $.362^{* *}$ & $.348^{* *}$ & $.804^{* *}$ \\
\hline \multirow[t]{3}{*}{ Y_2 } & Sig. (2-tailed) & .000 & & .000 & .000 & .000 & .000 \\
\hline & $\mathrm{N}$ & 100 & 100 & 100 & 100 & 100 & 100 \\
\hline & Pearson Correlation & $.902^{* *}$ & $.779^{* *}$ & 1 & $.392^{* *}$ & $.396^{* *}$ & $.889^{* *}$ \\
\hline \multirow[t]{3}{*}{ Y_3 } & Sig. (2-tailed) & .000 & .000 & & .000 & .000 & .000 \\
\hline & $\mathrm{N}$ & 100 & 100 & 100 & 100 & 100 & 100 \\
\hline & Pearson Correlation & $.343^{* *}$ & $.362^{* *}$ & $.392^{* *}$ & 1 & $.489^{* *}$ & $.658^{* *}$ \\
\hline \multirow[t]{3}{*}{ Y_4 } & Sig. (2-tailed) & .000 & .000 & .000 & & .000 & .000 \\
\hline & $\mathrm{N}$ & 100 & 100 & 100 & 100 & 100 & 100 \\
\hline & Pearson Correlation & $.392^{* *}$ & $.348^{* *}$ & $.396^{* *}$ & $.489^{* *}$ & 1 & $.687^{* *}$ \\
\hline \multirow[t]{3}{*}{ Y_5 } & Sig. (2-tailed) & .000 & .000 & .000 & .000 & & .000 \\
\hline & $\mathrm{N}$ & 100 & 100 & 100 & 100 & 100 & 100 \\
\hline & Pearson Correlation & $.851^{* *}$ & $.804^{* *}$ & $.889^{* *}$ & $.658^{* *}$ & $.687^{* *}$ & 1 \\
\hline \multirow[t]{2}{*}{ Skor } & Sig. (2-tailed) & .000 & .000 & .000 & .000 & .000 & \\
\hline & $\mathrm{N}$ & 100 & 100 & 100 & 100 & 100 & 100 \\
\hline
\end{tabular}

**. Correlation is significant at the 0.01 level (2-tailed).

\subsection{Uji Reliabilitas}

Uji reliabilitas merupakan ukuran suat kestabilan dan konsistensi responden dalam menjawab hal yang berkaitan dengan konstruk-konstruk pertanyaan yang merupakan dimensi suatu variable dan disusun dalam suatu kuesioner. Jika nilai Alpha > 0,60 maka reliabel (Sujarweni 2015)

Tabel 5. Uji Validitas Tingkat Pengetahuan

Reliability Statistics

Sumber: hasil output SPSS for windows versi 20

\begin{tabular}{r}
\hline Cronbach's Alpha N of Items \\
$.745 \quad 5$
\end{tabular}

Tabel 6. Uji Validitas Kesadaran Halal Reliability Statistics

Sumber: hasil output SPSS for windows versi 20

\begin{tabular}{rr}
\hline Cronbach's Alpha N of Items \\
\hline $.594 \quad 5$
\end{tabular}

Tabel 7. Uji Validitas Sertifikasi Halal Reliability Statistics

Sumber: hasil output SPSS for windows versi 20

$\begin{array}{r}\hline \text { Cronbach's Alpha N of Items } \\ \hline .834 \quad 5 \\ \hline\end{array}$




\subsection{Uji Normalitas}

Data yang normal memiliki signifikan $>0,05$. Teknik yang digunakan peneliti antara lain Normal Probability Plot dan table uji Kolmogrov-smirnov untuk memperjelas dengan angka.

Tabel 8 Uji Normalitas

One-Sample Kolmogorov-Smirnov Test

Sumber: hasil output SPSS for windows versi 20

\begin{tabular}{llr}
\hline & & Unstandardized Residual \\
\hline $\mathrm{N}$ & Mean & 100 \\
Normal Parameters & $\mathrm{a}, \mathrm{b}$ & $0 \mathrm{E}-7$ \\
& Std. Deviation & 1.87455068 \\
& Absolute & .253 \\
Most Extreme Differences & Positive & .132 \\
& Negative & -.253 \\
Kolmogorov-Smirnov Z & & 2.529 \\
Asymp. Sig. (2-tailed) & & .161 \\
\hline
\end{tabular}

a. Test distribution is Normal.

b. Calculated from data.

Berdasarkan tabel diatas, diperoleh nilai signifikansi sebesar $0.161>0.05$. artinya, data penelitian berdistribusi normal karena signifikansi lebih besar dari 0.05. Maka uji normalitas terpenuhi dan analisis regresi dapat dilakukan.

\subsection{Uji Multikolinieritas}

Uji Multikolinieritas bertujuan mengetahui ada atau tidaknya variabel bebas yang memiliki kemiripan dengan variabel bebas lain dalam satu model. Model regresi yang baik seharusnya tidak memiliki kemiripan diantara variabel bebas.

\section{Tabel 9 Uji Multikolinieritas}

Coefficients $^{\mathrm{a}}$

Sumber: hasil output SPSS for windows versi 20

\begin{tabular}{lll}
\hline Model & \multicolumn{2}{c}{ Collinearity Statistics } \\
\cline { 2 - 3 } & Tolerance & VIF \\
\hline Tingkat_Pengetahuan & .850 & 1.176 \\
Kesadaran_Mahasiswa & .850 & 1.176 \\
\hline \multicolumn{2}{l}{ a. Dependent Variable: Sertifikat_Halal }
\end{tabular}

\subsection{Uji Heteroskedasitas}

Uji Heteroskedasitas bertujuan untuk menguji apakah dalam model regresi terjadi ketidaksamaan varian dengan pengamatan yang lain. Jika model regresi terdapat pola tertentu seperti titik-titik yang membentuk pola bergelombang atau melebar maka dapat disimpulkan adanya indikasi heteroskedastisitas. Tetapi, apabila data tidak tidak membentuk pola dan titik-titik menyebar pada bagian atas dan bawah angka 0 dibagian sumbu $\mathrm{Y}$ dapat disimpulkan tidak adanya indikasi heteroskedastisitas. 


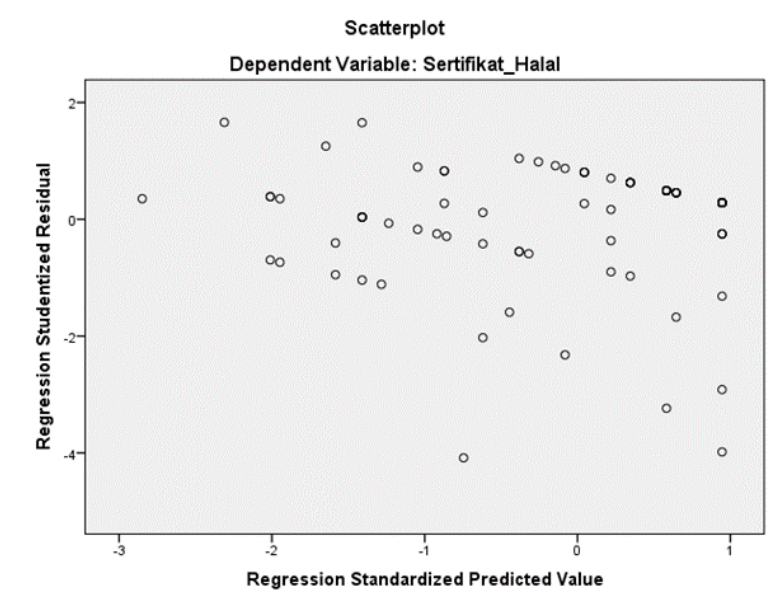

Sumber: hasil output SPSS for windows versi 20

\subsection{Uji Autokorelasi}

Uji Autokorelasi bertujuan untuk menguji apakah dalam model regresi linier berganda ada korelasi antara kesalahan penggunaan pada periode $t$ dengan kesalahan pada periode sebelumnya (t-1). Teknik yang digunakan dalam penelitian ini adalah Run Test.

Tabel 10. Uji Autokorelasi

Runs Test

Sumber: hasil output SPSS for windows versi 20

\begin{tabular}{lr}
\hline & Unstandardized Residual \\
\hline Test Value & .53088 \\
Cases $<$ Test Value & 37 \\
Cases $>=$ Test Value & 63 \\
Total Cases & 100 \\
Number of Runs & 46 \\
$Z$ & -.350 \\
Asymp. Sig. (2-tailed) & .727 \\
\hline a. Median
\end{tabular}

\subsection{Uji Statistik Deskriptif}

Analisis deskriptif merupakan alat uji analisis yang digunakan untuk memaparkan atau menggambarkan data yang terkumpul agar mudah dipahami. Berikut analisis deskriptif mengenai tingkat pengetahuan, kesadaran halal, dan sertifikasi halal.

Tabel 11. Statistik Deskriptif

Descriptive Statistics

Sumber: hasil output SPSS for windows versi 20

\begin{tabular}{llrrrr}
\hline & N & Minimum & Maximum & Mean & Std. Deviation \\
\hline Tingkat_Pengetahuan & 100 & 16 & 25 & 23.40 & 2.065 \\
Kesadaran_Mahasiswa & 100 & 19 & 25 & 23.72 & 1.596 \\
Sertifikat_Halal & 100 & 15 & 25 & 23.45 & 2.162 \\
Valid N (listwise) & 100 & & & & \\
\hline
\end{tabular}




\section{Penutup}

Dalam penelitian yang mengunakan analisis kuantitif dengan metode menyebar kuisioner dan mengambil beberapa sampel responden yang berjumlah 100 orang dari mahasiswa UIN bandung dengan syarat merupakan seorang yang pernah membeli atau memakai suatu produk. Dapat disimpulakan dari perhitungan diatas berdasarkan uji korelasi Pengetahuan mahasiswa dan Kesadaran secara simultan berpengaruh terhadap pembelian produk bersertifikat halal. Berdasarkan uji determinasi pengetahuan mahasiswa berpengaruh signifikan secara parsial terhadap pembelian produk bersertifikasi halal masing masing berjumlah 0,589 dan 34,7\%. Terdapat perbedaan dari pengetahuan mahasiswa terhadap pangan halal yang dimiliki. Berdasarkan pemahaman Pendidikan dan kesadaran memiliki tingkat kriteria yang baik dibandingkan dengan faktor pengetahuan lain seperti pengalaman, informasi dan lingkungan memiliki keriteria yang cukup. Dan hasilnya indeks komulatif pengetahuan mahasiswa berada di kriteria cukup. Sama halnya dengan hubungan antara pengetahuan mahasiswa terhadapa sertifikasi produk halal dengan ketepatan korelasi munujukan hubungan yang cukup.

Penelitian ini menghasilkan kesimpulan bahwa, secara parsial literasi halal dan religiositas berpengaruh secara signifikan terhadap konsumsi produk halal pada Mahasiswa MKS UIN Sunan Gunung Djati Bandung, kedua variabel berdasarkan hasil penelitian memiliki tingkat signifikansi 0,000 dan t hitung $>\mathrm{t}$ tabel. Kemudian secara simultan, literasi halal dan religiositas memiliki pengaruh yang juga signifikan terhadap konsumsi produk halal pada Mahasiswa MKS UIN Sunan Gunung Djati Bandung, kedua variabel memiliki korelasi yang sangat kuat terhadap konsumsi produk halal dan mampu berkontribusi menjelaskan variabel dependen sebesar 80,7\%. Implikasi penelitian ini menunjukkan bahwa dalam melihat tingkat konsumsi produk halal pada Mahasiswa MKS UIN Sunan Gunung Djati Bandung khususnya disini Mahasiswa MKS angkatan 2017, bahwa literasi atau pengetahuan tentang konsep halal menjadi sangat penting. Selain itu, religiositas disini menunjukkan bahwa mahasiswa MKS angkatan 2017 memiliki tingkat kesolehan yang mampu mempengaruhi konsumsi produk halalnya. Kemudian, hal ini juga menunjukkan bahwa mahasiswa MKS UIN Sunan Gunung Djati Bandung sangat memperhatikan kehalalan suatu produk terbukti dengan tingkat literasi halal yang mempengaruhi, dan juga secara kerohanian dengan latar belakang kampus islam mahasiswa MKS sangat berhati-hati dan mengkonsumsi produk.

\section{Daftar Pustaka}

Basu, Sudipta. (1997). The Conservatism Principle and The Asymetric Timelines of Earnings. New York: Journal of Accounting and Economics, Vol. 24, pp. 3 - 37.

Ahmad, N. A. B., Abaidah, T. N. B. T., \& Yahya, M. H. B. A. (2013). A Study

On Halal Food Awareness Among Muslim Customers In Klang. $4^{\text {th }}$ International Conference on Business And Economic Research (4th Icber 2013) Proceedin, (March), 1073-1087.

Amarul, Sukirno dan Denny Kurnia. "Understanding the Awareness of the Importance of Halal Labels to Business Actoers Based on range of LongBusiness V ariations", Business and Management Research, Vol. 8, No. 1, Januari, 2019.

Aldrin, Neil. (2015). Design Your Life. Jakarta: Puspa Swara.

Department Agama R.I. 2003. Panduan Sertifikasi Halal. Jakarta.

Leigh, R.W. (2004). Melayani dengan Efektif. Semarang: Gunung Mulia.

Legris, P., Ingham, J., \& Collerette, P. (2003). Why do people use information technology? A critical review of the technology acceptance model. Journal of Information \& Management, 40, 191-204

Setyaningsih, E. D. (2019). The Effect of Halal Certification and Halal Awareness Through Interest 
Decisions on Buying Halal Food Products. Universitas Bina Saran Informatika.

Talisa Rahma Pramintasari dan Indah Fatmawati, "Pengaruh Keyakinan Religius, Peran

Sertifikasi Halal, Paparan Informasi, dan Alasan Kesehatan Terhadap Kesadaran Masyarakat pada Produk Makanan Halal”, 2017, Vol. 8/ no. 1, 20-21.

Mahwiyah, "Pengaruh Lebelisasi Halal Terhadap Keputusan Pembelian Konsumen Studi Pada Dosen Fakultas Syari'ah dan Hukum, Univesitas Islam Negeri Syarif Hidayatullah Jakarta, 2010.

Notoatmodjo, S. 2003 Pendidikan dan perilaku Kesehatan. Jakarta: Rineka Cipta.

Pramintasari, T. R., \& Fatmawati, I. (2017). Pengaruh Keyakinan Religius, PeranSertifikasi Halal, Paparan Informasi, dan Alasan Kesehatan Terhadap

Kesadaran Masyarakat Pada Produk Makanan Halal. 8(1), 1-33.Waskito, D. (2015). Pengaruh Sertifikasi Halal, Kesadaran Halal, Dan Bahan Makanan Terhadap Minat Beli Produk Makanan Halal (Studi Pada Mahasiswa Muslim Di Yogyakarta). 